\title{
Laparoscopy-assisted versus open D2 radical gastrectomy for advanced gastric cancer without serosal invasion: a case control study
}

Qi-Yue Chen, Chang-Ming Huang ${ }^{*}$ Jian-Xian Lin, Chao-Hui Zheng, Ping Li, Jian-Wei Xie, Jia-Bin Wang and Jun Lu

\begin{abstract}
Background: The application of laparoscopic surgery for advanced gastric cancer (AGC) remains questionable on account of technical difficulty of D2 lymphadenectomy, and there has been few large-scale follow-up results regarding the oncological adequacy of laparoscopic surgery compared with that of open surgeries for AGC. The aim of this study is to evaluate technical feasibility and oncological efficacy of laparoscopy-assisted gastrectomy (LAG) for advanced gastric cancer without serosal invasion.
\end{abstract}

Methods: From January 2008 to December 2012, 1114 patients with gastric cancer underwent D2 gastrectomy, including 336 T2 and T3 patients in term of depth of invasion. Of all 336 patients, 224 underwent LAG, while open gastrectomy (OG) performed on the other 112 patients. The comparison was based on the clinicopathologic characteristics, surgical outcome, and follow-up results.

Results: There are not significant differences in clinicopathological characteristics between the two groups $(P>0.05)$. The operation time and first ambulation time was similar in the two groups. However, estimated blood loss, bowel function recovery time and duration of hospital stay were significantly less in the LAG group. No significant difference in morbidity and mortality was found between the LAG group and OG group (11.1\% vs. $15.3 \%, P=0.266 ; 0.9 \%$ vs. $1.8 \%, P=0.859)$. The mean number of resected lymph nodes (LNS) between the LAG group and $\mathrm{OG}$ group was similar (30.6 \pm 10.1 vs. $30.3 \pm 8.6, \mathrm{P}=0.786)$. Furthermore, the mean number of removed LNS in each station was not significantly different in the distal gastrectomy and total gastrectomy $(P>0.05)$. No statistical difference was seen in 1 year survival rate $(91.5 \%$ vs. $89.8 \% \mathrm{P}>0.05)$ and the survival curve after surgery between the LAG group and OG group.

Conclusion: Laparoscopy-assisted D2 radical gastrectomy is feasible, effective and has comparative oncological efficacy compared with open gastrectomy for advanced gastric cancer without serosal invasion.

Keywords: Stomach neoplasms, Gastrectomy, Laparoscopy, Lymph node, D2 dissection

\section{Background}

Since laparoscopy-assisted gastrectomy (LAG) for early gastric cancer was initially reported in 1994 [1], it has been increasingly used to treat early gastric cancer as it is less invasive than conventional open gastrectomy (OG) $[2,3]$. However, its wider acceptance as an alternative to the open approach remains contentious. The reasons for slow acceptance of this procedure include concerns about safety and doubts about the effectiveness of lymphadenectomy

\footnotetext{
*Correspondence: hcmlr2002@163.com

Department of Gastric Surgery, Fujian Medical University Union Hospital, No.29 Xinquan Road, Fuzhou, Fujian Province 350001, China
}

compared to conventional open gastrectomy. This study compared the clinical features of 224 patients who underwent LAG with 112 patients who underwent OG with D2 lymph node dissection, for pathologically confirmed stage T2-3 gastric carcinoma. The aim of this study was to evaluate the feasibility and short-term outcome of LAG for advanced gastric cancer (AGC) without serosal exposure.

\section{Methods \\ Materials}

From January 2008 to December 2010, 1,114 patients diagnosed with primary gastric cancer were treated with

\section{Biomed Central}


curative resection (R0) at the department of Gastric Surgery, Fujian Medical University Union Hospital, Fuzhou, China. Of these patients, 336 had pathologically confirmed stage T2 (depth of invasion in submucosa) or T3 (depth of invasion in muscularis propria) cancer according to the 7th edition of the Union for International Cancer Control (UICC) [4]; of the 336 patients, 224 underwent LAG, and 112 patients underwent OG. Selection of laparoscopic versus the open approach for patients diagnosed preoperatively with AGC was by patient choice.

Nodal material was separately dissected from the enbloc specimen at the end of the procedure by the surgeons, and the remaining nodes were identified and retrieved by specialized pathologists from formalin-fixed surgical specimens without using any specific technique to increase nodal retrieval rate. The lymph nodes of the stomach are defined and given station numbers according to the 3rd English edition of Japanese classification of gastric carcinoma [5]. Staging was done according to the 7th edition of the UICC tumor, mode, metastasis (TNM) classification [4]. Postoperative complications have been classified using the therapy-oriented severity grading system (TOSGS) as follows: grade 1, no need for specific intervention; grade 2 , need for drug therapy such as antibiotics; grade 3, need for invasive therapy; grade 4, organ dysfunction with ICU stay; grade 5, death. This type of system is applied in medical oncology and has resulted in the National Cancer Institute's uniform system of complication reporting.

All procedures were performed after obtaining informed consent following the explanation of the surgical and oncologic risks. Inclusion criteria were as follows: histologically confirmed adenocarcinoma of the stomach; pathologically confirmed stage T2-T3; no evidence of distant metastasis by means of abdominal computed tomography(CT) and/or abdominal ultrasound and posteroanteriorchest radiograph; D2 lymphadenectomy with curative R0 according to pathological diagnosis after the operation. Exclusion criteria were as follows: intraoperative evidence of peritoneal disseminated or distant metastasis; incomplete of pathological data; diagnosis of positive serosal invasion during the operation. Follow-up was carried out by trained investigators through mailings, telephone calls, visits to patients or recording of the patients' consultations at the outpatient service every 6 months. The survival time was the time from the surgical intervention until the last contact, the date of death, or the date that the survival information was collected.

\section{Surgical procedure}

The D2 lymphadenectomy was always performed according to the lymph node classification of the
Japanese Gastric Cancer Association [5]. All operations were performed under general anesthesia. Patients were placed in the supine position, with legs apart and 20 to $30^{\circ}$ head-up tilt. The surgeon stood on the left of the patient, the assistant surgeon stood on patient's right, and the videolaparoscope operator stood between the patient's legs. Five trocars were used; one $10-\mathrm{mm}$ trocar for the laparoscope was inserted below the umbilicus. One 12-mm trocar was inserted in the left pre-axillary line $2 \mathrm{~cm}$ below the costal margin as a major hand port. A 5-mm trocar was placed at the contralateral site for traction and exposure of the liver. A 5-mm trocar was inserted as an accessory port in the left and right mid clavicular line $2 \mathrm{~cm}$ above the level of the umbilicus.

\section{Laparoscopic total gastrectomy}

The stomach and the peritoneal cavity were inspected to rule out adjacent organ invasion and peritoneal seeding using a $30^{\circ}$ forward oblique laparoscope. Then under pneumoperitoneum of 12 to $15 \mathrm{mmHg}$, the gastrocolic ligament was divided using ultrasonic-activated scissors along the border of the transverse colon, thus including the greater omentum in the specimen to be resected. The dissection moved to the hepatic flexure and the pylorus. Then the superior leaf of the mesocolon was dissected. After the right gastroepiploic vein was exposed and divided with double clips, the right gastroepiploic artery was vascularized and cut with titanium clips at its origin from the gastroduodenal artery, just above the pancreatic head, to dissect Group 6 (Figure 1). The stomach was lifted upwards (towards the head)to expose the gastropancreatic fold. The left gastric vein was carefully prepared and separately divided at the upper border of the pancreatic body and then the left gastric artery was vascularized to remove Group 7. The lymph nodes along the proximal splenic artery (Group 11p) were removed. Subsequently, the dissection was continued to the right along the artery to remove the nodes along the celiac axis and the common hepatic artery (Group 9, 8a). The right gastric artery was then exposed and divided at its origin with double clips, thus creating room for the dissection of the suprapyloric lymph nodes (Group 5). Along the border of the liver, the lesser omentum was dissected and the lymph nodes of the anterior region of the hepatoduodenal ligament (Group 12a) were dissected and removed (Figure 2). The dissection was continued toward the distal pancreas to uncover the distal splenic artery and splenic vein, then the fatty connective tissue, including the lymph nodes along the distal splenic artery (Group 11d) and the lymph nodes around splenic hilum (Group 10), were completely removed. The left gastroepiploic artery, posterior gastric artery, and all short gastric vessels were divided with either harmonic scissors or clips, and the lymph nodes were removed 


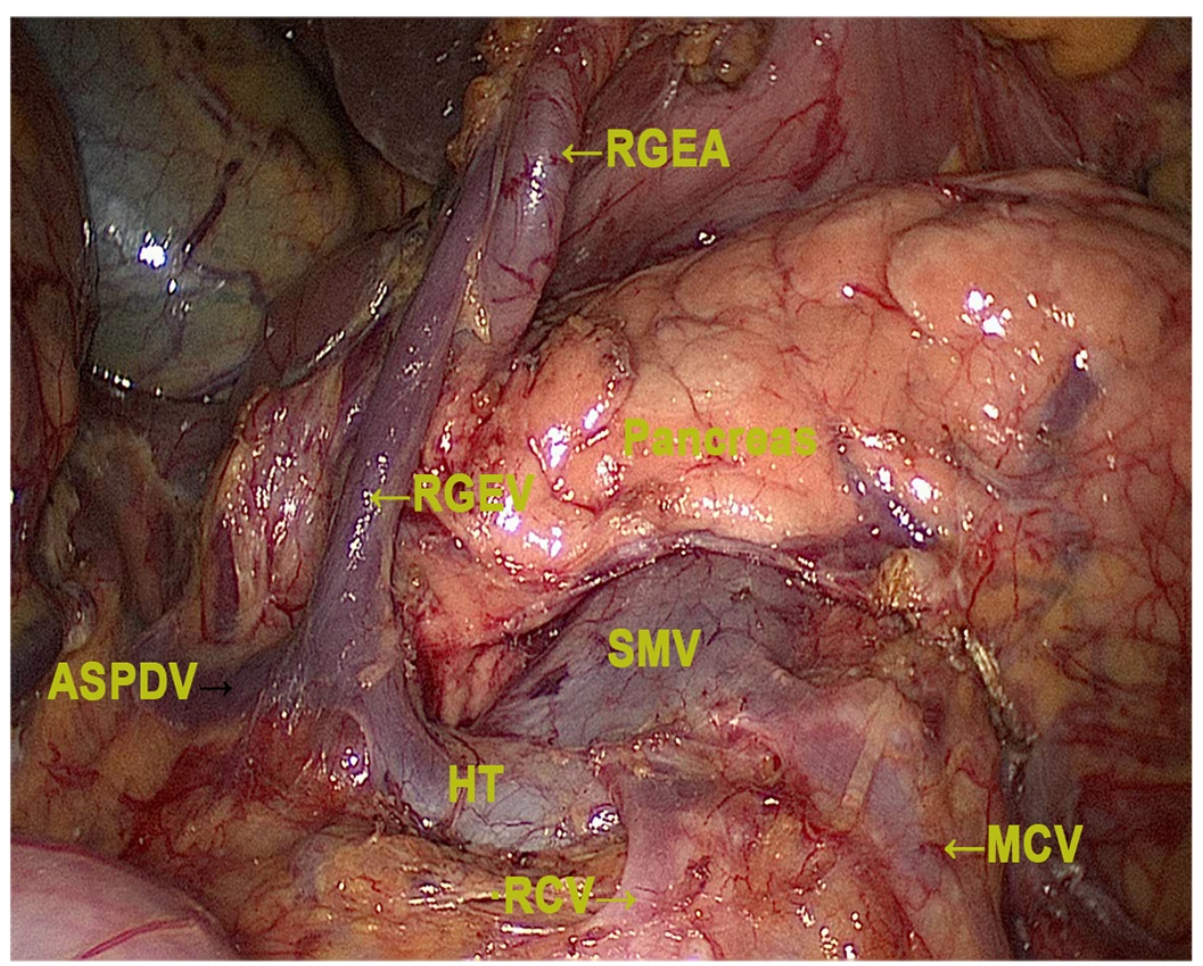

Figure 1 Dissection of lymph node number 6. RGEV, right gastroepiploic vein; RGEA, right gastroepiploic artery; ASPDV, anterior superior pancreaticoduodenal vein; SMV, superior mesenteric vein; RCV, right colic vein; HT, Herne's trunk; MCV, middle colic vein.

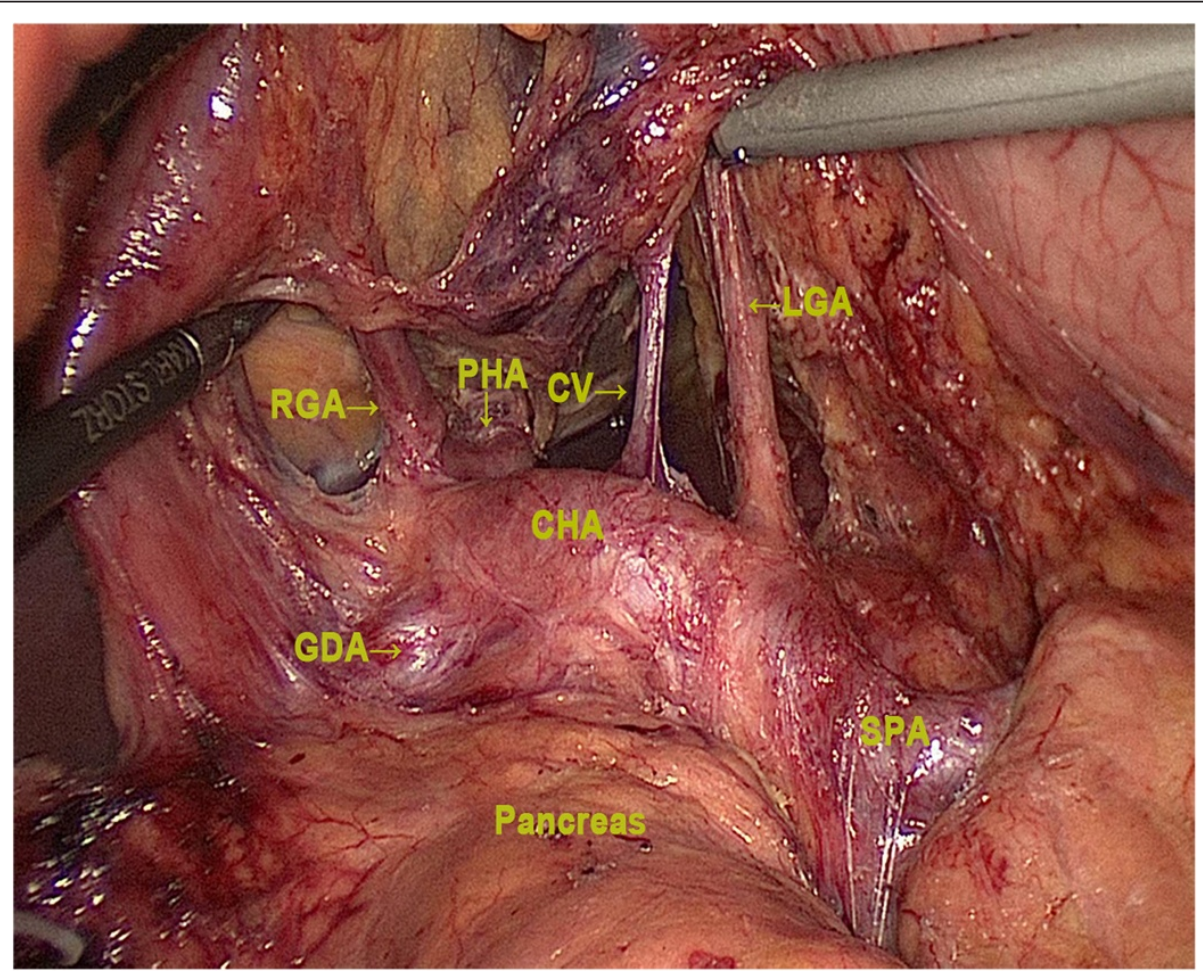

Figure 2 Dissection of lymph nodes numbers7, 8a, 9, 12a, 11p. LGA, left gastric artery; RGA, right gastric artery; CV, coronary vein; CHA, common hepatic artery; PHA, proper hepatic artery; GDA, gastroduodenal artery; SPA, splenic artery. 
(Group 4sa, 4sb) (Figure 3). Before gastric transection, the cardiac nodes were dissected enbloc including the right cardiac (Group 1) and left cardiac nodes (Group 2). After dissection of the gastric and gastroepiploic vessels, the phrenoesophageal membrane and vagal nerve were divided.

\section{Laparoscopic distal gastrectomy}

All steps were performed as in the total gastrectomy procedure but without the mobilization of the distal esophagus, gastric fundus and Group10, 11d and some Group 4sa lymph nodes. The stomach proximal transection site was selected according to the location of the tumor and the procedure was performed with a linear stapler.

After the laparoscopic operation, a small laparotomy incision was made under the xyphoid $(5$ to $7 \mathrm{~cm}$ ). Distal gastrectomy with Billroth I, Billroth II or total gastrectomy with Roux-en-Y anastomosis were extra corporeally performed using the hand-sewn method. The specimen was pulled out of the peritoneal cavity through the small laparotomy incision. OG was performed using the same methods as LAG. The region of lymphadenectomy in OG was mostly the same as that for LAG.

\section{Statistical analysis}

All statistical analyses were conducted using the statistical program SPSS 18.0. The data were collected and expressed as mean \pm SD. A statistical analysis was performed using the chi-square test, or the unpaired Student's $t$-test as appropriate. Survival was evaluated using the Kaplan-Meier method, including the log-rank test for model. $P<0.05$ was considered statistically significant.

\section{Results}

\section{Patient clinicopathologic characteristics}

The clinicopathologic characteristics of the patients are presented in Table 1. The series included 72 men and 264 women, with a mean age of 61.3 years (range 32 to 89 years). The age, gender, resection extent, tumor depth, tumor size, body mass index (BMI), location of neoplasm, gross type, histologic type, American Society of Anesthesiologists(ASA) score, comorbidity, lymph node status ( $\mathrm{N}$ stage), TNM stage and gastrointestinal reconstruction type did not differ between the LAG group and OG group $(P>0.05)$.

\section{Intraoperative and postoperative characteristics}

The operation time and first ambulation time did not differ between the LAG group and OG group. However, estimated blood loss, transfusion amounts, bowel function recovery time and duration of hospital stay were significantly lower in the LAG group $(P<0.05)$ (Table 2$)$.

\section{Morbidity and mortality}

The overall postoperative morbidity and mortality rates among all patients were $12.5 \%$ and $1.2 \%$, respectively.

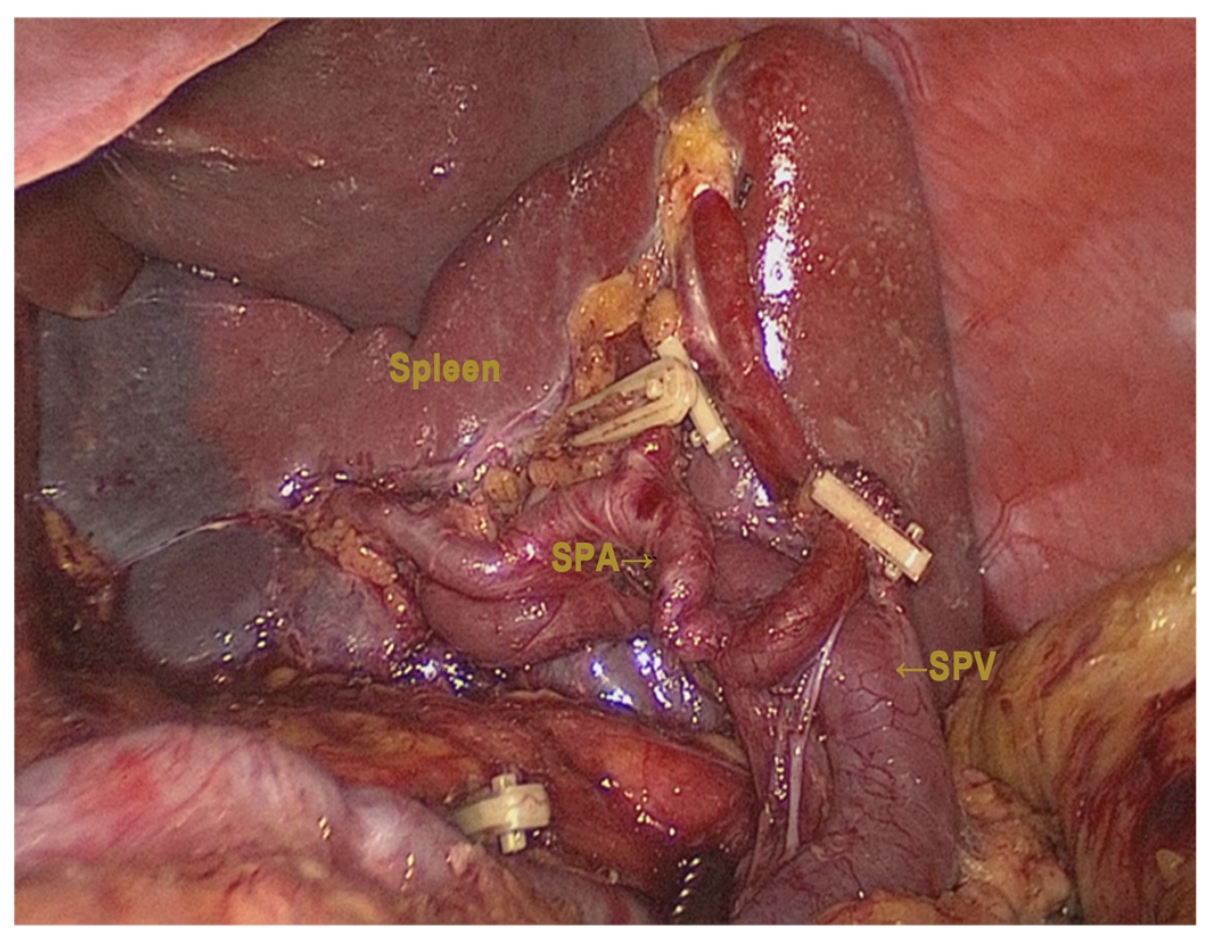

Figure 3 Dissection of the splenic hilum preserving the splenic artery and vein. SPA, splenic artery; SPA, splenic vein. 
Table 1 Patient clinicopathological characteristics

\begin{tabular}{|c|c|c|c|}
\hline Characteristics & $\operatorname{LAG}(n=224)$ & $O G(n)=112$ & $P$-value \\
\hline Sex: & & & 0.778 \\
\hline Female $(n)$ & 175 & 89 & \\
\hline Male (n) & 49 & 23 & \\
\hline Age(years, mean \pm SD) & $61.6 \pm 10.6$ & $60.8 \pm 10.2$ & 0.525 \\
\hline Tumor size $(\mathrm{cm}$, mean $\pm \mathrm{SD})$ & $4.7 \pm 2.0$ & $4.4 \pm 2.0$ & 0.631 \\
\hline Body mass index $\left(\mathrm{kg} / \mathrm{m}^{2}\right)$ & 22.3 & 22.0 & 0.498 \\
\hline Tumor location (n): & & & 0.083 \\
\hline Greater curvature & 82 & 52 & \\
\hline Lesser curvature & 143 & 60 & \\
\hline Gross type $(n)$ : & & & 0.450 \\
\hline Elevated & 50 & 21 & \\
\hline Depressed & 174 & 91 & \\
\hline Histology (n): & & & 0.875 \\
\hline Differentiated & 37 & 17 & \\
\hline Undifferentiated & 187 & 95 & \\
\hline ASA score (n): & & & 0.857 \\
\hline 1 & 122 & 58 & \\
\hline 2 & 94 & 49 & \\
\hline 3 & 8 & 5 & \\
\hline Comorbidities (n): & & & 0.643 \\
\hline $\begin{array}{l}\text { Presence of one or } \\
\text { more comorbidities }\end{array}$ & 102 & 54 & \\
\hline Hypertension & 43 & 16 & \\
\hline Diabetes mellitus & 17 & 10 & \\
\hline Dyslipidemia & 19 & 12 & \\
\hline Cardiovascular & 6 & 6 & \\
\hline Pulmonary & 8 & 5 & \\
\hline Liver & 5 & 3 & \\
\hline Others & 4 & 2 & \\
\hline Tumor depth (n): & & & 0.133 \\
\hline $\mathrm{T} 2$ & 81 & 50 & \\
\hline T3 & 143 & 62 & \\
\hline$N$ stage $(n)$ : & & & 0.681 \\
\hline NO & 81 & 41 & \\
\hline N1 & 42 & 25 & \\
\hline N2 & 47 & 25 & \\
\hline N3 & 54 & 21 & \\
\hline TNM stage $(n)$ : & & & 0.958 \\
\hline $\mathrm{Ib}$ & 40 & 25 & \\
\hline Ila & 56 & 26 & \\
\hline$\| \mathrm{b}$ & 43 & 25 & \\
\hline Illa & 41 & 20 & \\
\hline Illb & 44 & 16 & \\
\hline Resection extent (n): & & & 1.000 \\
\hline TG & 106 & 61 & \\
\hline$\overline{D G}$ & 118 & 51 & \\
\hline
\end{tabular}

Table 1 Patient clinicopathological characteristics (Continued)

\begin{tabular}{lccc}
\hline Reconstruction $(\mathrm{n}):$ & & & 0.058 \\
\hline Billrothl & 101 & 37 & \\
\hline Billrothll & 16 & 14 \\
\hline Roux-y & 107 & 61 & \\
\hline
\end{tabular}

n, number of patients; ASA, American Society of Anesthesiologists; DG, distal gastrectomy; TG, total gastrectomy; TNM, tumor, node metastasis staging; LAG, laparoscopy-assisted gastrectomy; $\mathrm{OG}$, open gastrectomy. $P$-values are for comparison of the LAG and OG groups.

The postoperative complications were not different between the LAG and OG groups $(11.1 \%$ vs. $15.3 \%, P=$ 0.266 ), and we also observed no difference between the two groups using TOSGS. The mortality rate in the LAG group was $0.9 \%$ compared with $1.8 \%$ in the OG group, but the difference was not statistically significant $(P=0.859)$ (Table 3$)$.

\section{Dissection of lymph nodes}

The mean number of harvested lymph nodes was $30.5 \pm$ 9.6 in all patients with a median of 29 (range 10 to 64). The mean number of retrieved lymph nodes was not different between the two groups $(30.6 \pm 10.1$ in the LAG group vs. $30.3 \pm 8.6$ in the OG group) $(P=0.786)$. Furthermore, the mean number of removed lymph nodes in each station was not significantly different in distal gastrectomy or total gastrectomy $(P>0.05)$ (Figure 4,5$)$.

\section{Survival time}

The follow-up rate was $98.9 \%$ (316 patients). Of these, the LAG follow-up rate was $94.6 \%$ (212 patients) and the OG follow-up rate was $92.9 \%$ (104 patients). The median follow-up period was 19 months (range 1 to 48 months). The respective 1-year survival rates were 91.5\% (LAG) and 89.8\% (OG).There was no significant differences in the overall survival curve between the two groups (Figure 6) $(P=0.297)$.

\section{Discussion}

LAG shares obvious advantages of being minimally invasive and has the same short- and long-term efficacy compared with traditional open surgery in the treatment of early gastric cancer [6-9].Therefore, it has gradually become acknowledged by counterpart clinicians. Since 2002, the Japanese gastric cancer treatment guidelines have recommended laparoscopy-assisted gastrectomy as the standard procedure for early gastric carcinoma.

As experience with LAG for early gastric cancer has substantially increased, some surgeons have become concerned about laparoscopic surgery for AGC [10-14]. Ninety percent of patients diagnosed with gastric carcinoma in China have advanced-stage disease. The study of laparoscopic techniques in AGC would seem sensible 
Table 2 Intraoperative and postoperative characteristics

\begin{tabular}{lccc}
\hline Variables & LAG $(\mathbf{n}=\mathbf{2 2 4})$ & $\mathbf{O G}(\mathbf{n}=\mathbf{1 1 2})$ & $\boldsymbol{P}$-value \\
\hline Operation time(minutes) & $207.2 \pm 137.3$ & $213.0 \pm 54.7$ & 0.667 \\
\hline Blood loss $(\mathrm{ml})$ & $82.7 \pm 101.3$ & $201.7 \pm 235.3$ & 0.0 \\
\hline Transfused patients $(\mathrm{n})$ & 4 & 8 & 0.029 \\
\hline Time to first ambulation $\left(\right.$ days $\left.^{1}\right)$ & $2.7 \pm 1.2$ & $2.9 \pm 1.2$ & 0.099 \\
\hline Time to first flatus (days $^{1}$ ) & $2.6 \pm 1.1$ & $3.2 \pm 1.1$ & 0.0 \\
\hline Time to fluid diet $\left(\right.$ days $^{1}$ ) & $4.7 \pm 1.5$ & $5.1 \pm 1.8$ & 0.034 \\
\hline Time to soft diet $\left(\right.$ days $^{1}$ ) & $8.7 \pm 1.6$ & $10.3 \pm 1.6$ & 0.0 \\
\hline Hospital stay $\left(\right.$ days $^{1}$ ) & $13.3 \pm 5.7$ & $17.4 \pm 5.0$ & 0.0 \\
\hline
\end{tabular}

Results are presented as mean $\pm S D$ unless stated otherwise ${ }^{1}$ Postoperative days; $n$, number of patients; $P$-values are for comparison of the LAG and OG groups.

Current evidence is compatible with D2 lymph node dissection as the preferred treatment for fit patients with AGC, in centers that can demonstrate low operative mortality $[15,16]$. Furthermore, the Japanese gastric

Table 3 Morbidity and mortality

\begin{tabular}{|c|c|c|c|}
\hline Variables & $\operatorname{LAG}(n=224)$ & $O G(n=112)$ & P-value \\
\hline Surgical complication & 10 & 11 & 0.056 \\
\hline Duodenal stump fistula & 1 & 1 & \\
\hline Anastomotic leakage & 1 & 1 & \\
\hline Pancreatic fistula & 1 & 1 & \\
\hline Lymphatic fistula & 2 & 3 & \\
\hline Abdominal infection & 2 & 1 & \\
\hline Gastric stasis & 1 & 1 & \\
\hline Anastomotic bleeding & 1 & 1 & \\
\hline Anastomotic stenosis & 1 & 1 & \\
\hline Intestinal obstruction & 0 & 1 & \\
\hline Surgical complication grade & & & 0.277 \\
\hline TOSGS 1 & 6 & 3 & \\
\hline TOSGS 2 & 4 & 7 & \\
\hline TOSGS 3 & 0 & 1 & \\
\hline TOSGS 4 & 0 & 0 & \\
\hline TOSGS 5 & 0 & 0 & \\
\hline Medical complication & 15 & 6 & 0.633 \\
\hline Pneumonia & 13 & 4 & \\
\hline Septicemia & 1 & 0 & \\
\hline Angiocardiopathy & 1 & 1 & \\
\hline $\mathrm{DIC}$ & 0 & 1 & \\
\hline Medical complication grade & & & 0.590 \\
\hline TOSGS 1 & 8 & 2 & \\
\hline TOSGS 2 & 5 & 2 & \\
\hline TOSGS 3 & 0 & 0 & \\
\hline TOSGS 4 & 0 & 0 & \\
\hline TOSGS 5 & 2 & 2 & \\
\hline Mortality & 2 & 2 & 0.859 \\
\hline
\end{tabular}

Results presented as number of patients DIC, disseminated intravascular coagulation; TOSGS, therapy-oriented severity grading system. $P$-values are for comparison of the LAG and OG groups. cancer treatment guidelines have adopted D2 lymph node dissection as the standard technique for AGC. However, the application of laparoscopic surgery for AGC remains questionable on account of the technical difficulty of D2 lymphadenectomy, and there has been few large-scale follow-up data on the oncologic adequacy of laparoscopic surgery compared with that of open surgery for AGC. Nevertheless, some small case-studies also showed that laparoscopic D2 lymphadenectomy is a safe procedure for AGC if the surgery is performed by experienced surgeons $[13,17,18]$. The Japanese gastric cancer treatment guidelines regard LAG as an investigational treatment [19]. Some scholars [20-22] studying the laparoscopic learning curve have found that once surgeons span the learning curve reaching a plateau phase, the superiority of laparoscopic gastric carcinoma surgery will gradually appear more often compared with open surgery.

We have been performing LAG for gastric cancer since 2007. In the present study, we selected patients treated after January 2008, by which time we had overcome the learning curve having performed approximately 300 laparoscopic D2 gastrectomy procedures for gastric cancer, to reduce the influence of lack of surgical experience on the results. In this study, we compared 224 patients who underwent LAG with 112 who underwent OG for AGC without serosal exposure, in the same period. The data show that the LAG and OG groups shared similar operating times and first ambulation times, while the LAG group had less intraoperative blood loss, earlier recovery time for bowel movement, and a shorter postoperative stay in hospital. LAG was also shown to have obvious advantages of being minimally invasive for treatment of AGC without invasion of serosa.

The incidence of postoperative morbidity and mortality in the LAG group in the present study was similar to that of other reports. Although no significant difference in postoperative morbidity or mortality was observed between the LAG and OG groups $(11.1 \%$ vs. $15.3 \%$, and $0.9 \%$ vs. $1.8 \%$, respectively, $P>0.05$ ), our results show that LAG for AGC has similar intraoperative and postoperative complications to open surgery, and may even be better than OG. LAG D2 radical lymphadenectomy is a safe technique with fast postoperative recovery in the treatment of AGC without invasion of serosa. Therefore, LAG for AGC may be acceptable from this viewpoint.

The advantages of minimally invasive laparoscopic surgery have gradually been recognized, but laparoscopic D2 lymph node dissection is difficult to handle due to the complicated vessels, numerous anatomical layers and the complex lymph node metastasis pathway around the stomach. Therefore, many scholars still doubt whether LAG can achieve as considerable a radical effect as open 


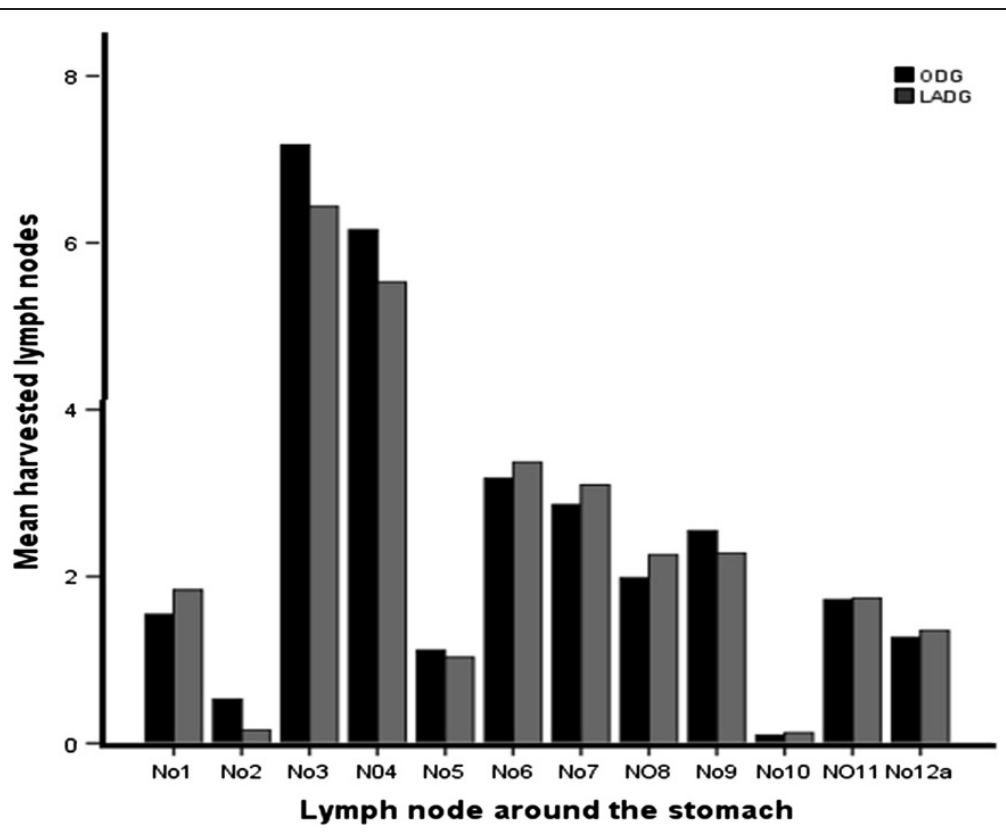

Figure 4 Distribution of harvested perigastric lymph nodes in the laparoscopy-assisted distal gastrectomy (LADG) and the open distal gastrectomy(ODG) groups. The mean number of removed lymph nodes in each station was not significantly difference between the two groups $(P>0.05)$.

surgery. Sato [23] compared 36 cases of laparoscopyassisted D2 lymph node dissection and 130 cases of open surgery for AGC. The average number of retrieved lymph node in the laparoscopic and open surgery group was $(32 \pm 12)$ and $(35 \pm 1)$ respectively, with no statistically significance difference. Martínez-Ramos [13] presented a meta-analysis comparing laparoscopy to open surgery, predominantly in AGC. The study demonstrated no significant differences between the two groups in the number of dissected lymph nodes (weighted mean

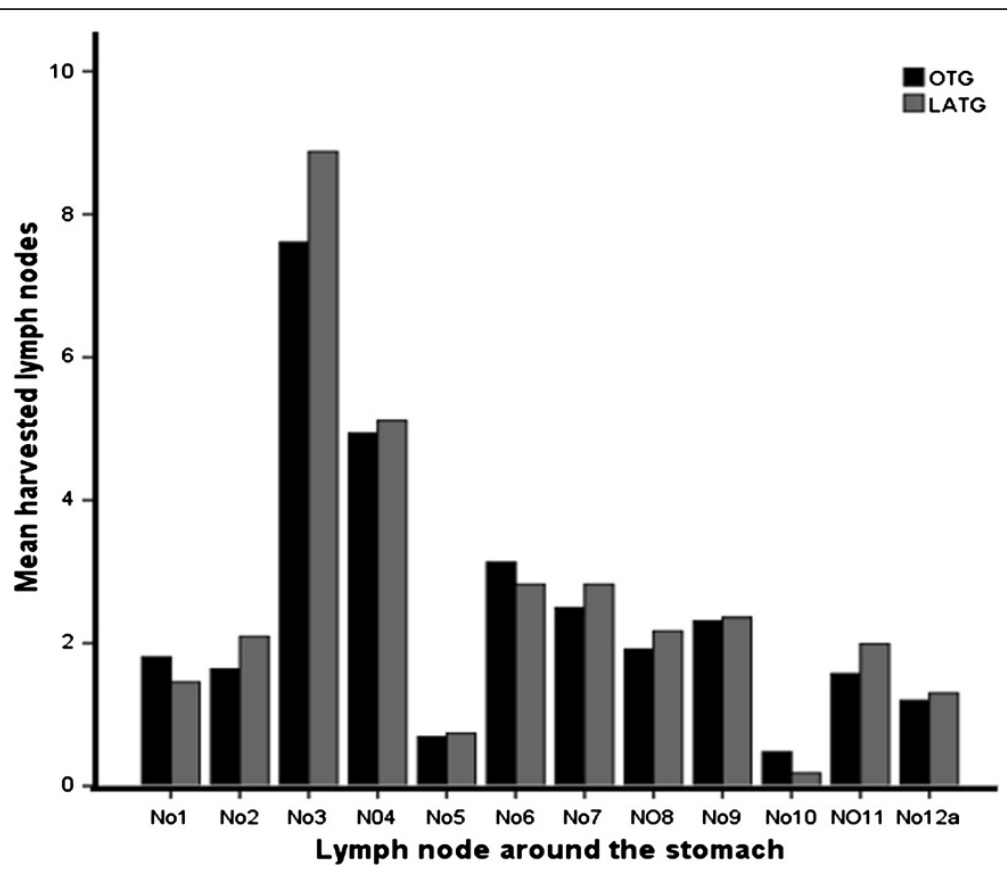

Figure 5 Distribution of harvested perigastric lymph nodes laparoscopy-assisted total gastrectomy (LATG) and the open total gastrectomy(OTG) groups. The mean number of removed lymph nodes in each station was not significantly different between the two groups. $(P>0.05)$. 


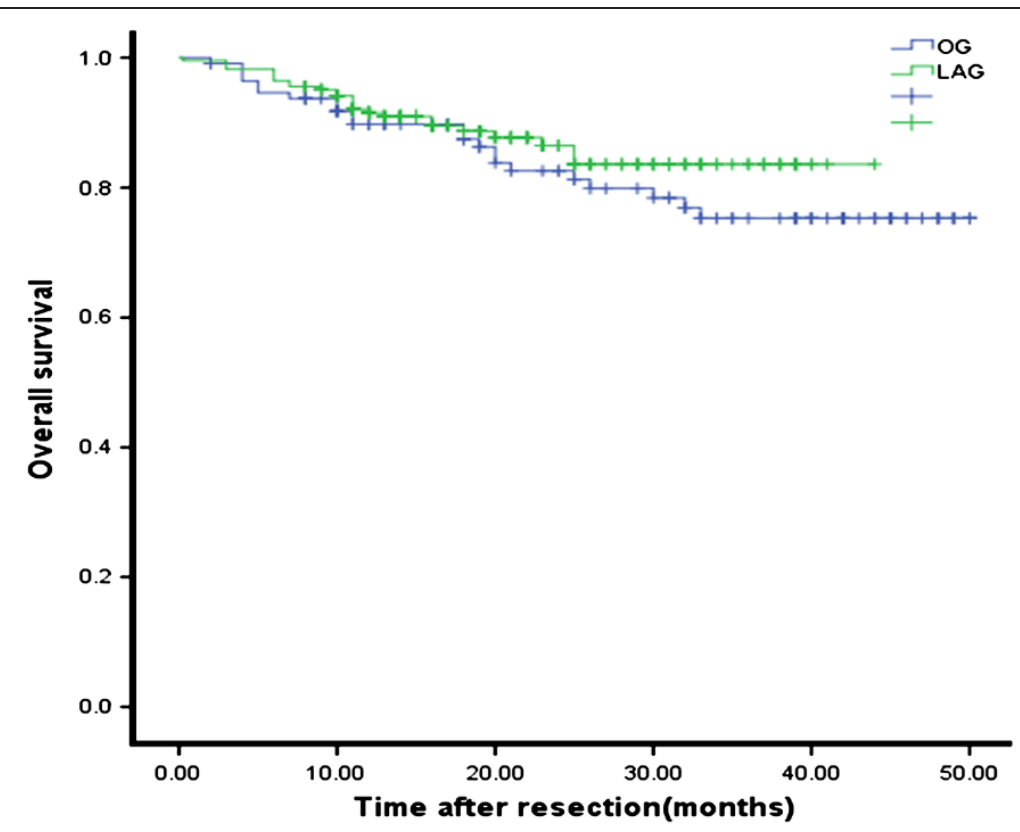

Figure 6 Overall survival curves for patients in the laparoscopy-assisted and the open gastrectomy groups. There were no significant differences in overall survival curve between the two groups $(P=0.297)$.

difference, WMD $-1.57,95 \%$ confidence interval -3.41 to $0.26, I$-squared $=8.3$ ). There studies suggested that LAG D2 radical surgery for AGC is feasible and safe and the number of harvested lymph nodes is the same as in open surgery. We found that skilled laparoscopic surgical technology and thorough palpation of anatomical layers under laparoscopy is the key to lymph node dissection. The laparoscopic amplification elaborately shows the finer structure of the vasculature, nerves and fascia, which helps surgeons to seek a specific fascia space and facilitates lymph nodes dissection in the vascular sheath. Furthermore, the ultrasonic scalpel is effective for cutting, for hemostasis and for minimizing damage to the surrounding tissues, which is suitable for vascular separation and lymph node dissection. The number of resected lymph nodes in our study was enough for curability and to determine lymph node metastasis. Our data show that the mean number of retrieved lymph nodes was not different between the LAG and OG group. Furthermore, the mean number of removed lymph nodes in each station was not significantly different with distal or total gastrectomy. For AGC without invasion of serosa, laparoscopy-assisted D2 lymphadenetomy is able to achieve the same effect on lymph node dissection as open surgery, regardless of the extent of the gastrectomy. The surgical approach (laparoscopy or open) did not appear to influence the lymph node yield.

To date, laparoscopic surgery for early gastric carcinoma has achieved favorable short- and long-term efficacy $[6-8,24,25]$. Although the efficacy of laparoscopic surgery for AGC is rarely reported, the results also show it can achieve almost the same short- and long-term efficacy as open surgery. Hur [26] compared 26 cases of laparoscopic surgery and 25 cases of open surgery for treatment of AGC. The 3-year survival rate in the laparoscopy and open surgery groups was $88.2 \%$ and $77.2 \%$ respectively, with no statistical difference. A case-control study reported by Shuang [27] demonstrated the same survival curve for laparoscopy versus open surgery during the same period and showed that laparoscopic surgery has similar long-term efficacy for treatment of AGC. Our study also showed that the survival curves for the LAG and OG groups were not significantly different $(P>0.05)$. LAG and OG have similar short survival times, but the long-term effect needs to be followed-up.

In summary, if surgeons are proficient in laparoscopic surgical techniques and comply with the principles of surgery, LAG D2 radical surgery can achieve similar, or even better effects compared to open surgery, and can achieve a comparative short-term clinical efficacy for treatment of AGC without serosal invasion. To establish laparoscopic surgery as a standard treatment for AGC, multicenter randomized controlled trials comparing the short- and long-term outcomes of laparoscopic versus open surgery are necessary.

\section{Conclusion}

Our study confirms laparoscopy-assisted D2 radical gastrectomy is feasible, effective and has comparative oncological efficacy compared with open gastrectomy for advanced gastric cancer without serosal invasion. 


\section{Abbreviations}

AGC: Advanced gastric cancer; ASA: American Society of Anesthesiologists; LAG: Laparoscopy-assisted gastrectomy; LNS: Lymph nodes; OG: Open gastrectomy; TNM: Tumor node, metastasis staging; TOSGS: Therapy-oriented severity grading system; WMD: Weighted mean difference; UICC: Union for International Cancer Control.

\section{Competing interests}

The authors declare they have no competing interests.

\section{Authors' contributions}

QYC, CMH and JXL conceived the study, analyzed the data, and drafted the manuscript; $\mathrm{CHZ}$ helped revise the manuscript critically for important intellectual content; PL, JWX, JBW and JL helped collect data and design the study. All authors read and approved the final manuscript.

Received: 14 September 2012 Accepted: 4 November 2012

Published: 16 November 2012

\section{References}

1. Kitano S, Iso Y, Moriyama M, Sugimachi K: Laparoscopy-assisted Billroth I gastrectomy. Surg Laparosc Endosc 1994, 4:146-148.

2. Lee $J$ H, Han HS: A prospective randomized study comparing open vs laparoscopy-assisted distal gastrectomy in early gastric cancer: early results. Surg Endosc 2005, 19:168-173.

3. Dulucq JL, Wintringer $P$, Stabilini C, Solinas L, Perissat J, Mahajna A: Laparoscopic and open gastric resections for malignant lesions: a prospective comparative study. Surg Endosc 2005, 19:933-938.

4. Sobin LH, Gospodarowicz MK, Wittekind C: TNM Classification of Malignant Tumours. New York: Wiley; 2009.

5. Japanese Gastric Cancer Association: Japanese classification of gastric carcinoma: 3rd English edition. Gastric Cancer 2011, 14:101-112.

6. Kitano S, Shiraishi N, Fujii K, Yasuda K, Inomata M, Adachi Y: A randomized controlled trial comparing open vs laparoscopy-assisted distal gastrectomy for the treatment of early gastric cancer: an interim report. Surgery 2002, 131:S306-311.

7. Han HS, Kim YW, Yi NJ, Fleischer GD: Laparoscopy-assisted D2 subtotal gastrectomy in early gastric cancer. Surg Laparosc Endosc Percutan Tech 2003, 13:361-365.

8. Kitano S, Shiraishi N, Uyama I, Sugihara K, Tanigawa N: A multicenter study on oncologic outcome of laparoscopic gastrectomy for early cancer in Japan. Ann Surg 2007, 245:68-72

9. Lee $\mathrm{JH}$, Yom CK, Han HS: Comparison of long-term outcomes of laparoscopy-assisted and open distal gastrectomy for early gastric cancer. Surg Endosc 2009, 23:1759-1763.

10. Uyama I, Sugioka A, Fujita J, Komori Y, Matsui H, Hasumi A: Laparoscopic total gastrectomy with distal pancreatosplenectomy and D2 lymphadenectomy for advanced gastric cancer. Gastric Cancer 1999, 2:230-234.

11. Uyama I, Sugioka A, Matsui H, Fujita J, Komori Y, Hasumi A: Laparoscopic D2 lymph node dissection for advanced gastric cancer located in the middle or lower third portion of the stomach. Gastric Cancer 2000, 3:50-55.

12. Scatizzi M, Kroning KC, Lenzi E, Moraldi L, Cantafio S, Feroci F: Laparoscopic versus open distal gastrectomy for locally advanced gastric cancer: a case-control study. Updates Surg 2011, 63:17-23.

13. Martinez-Ramos D, Miralles-Tena JM, Cuesta MA, Escrig-Sos J, Van der Peet D, Hoashi JS, Salvador-Sanchis JL: Laparoscopy versus open surgery for advanced and resectable gastric cancer: a meta-analysis. Rev Esp Enferm Dig 2011, 103:133-141.

14. Yoshimura F, Inaba K, Kawamura Y, Ishida Y, Taniguchi K, Isogaki J, Satoh S, Kanaya S, Sakurai Y, Uyama I: Clinical outcome and clinicopathological characteristics of recurrence after laparoscopic gastrectomy for advanced gastric cancer. Digestion 2011, 83:184-190.

15. Roukos DH, Lorenz M, Encke A: Evidence of survival benefit of extended (D2) lymphadenectomy in western patients with gastric cancer based on a new concept: a prospective long-term follow-up study. Surgery 1998 123:573-578.

16. Di Martino N, Izzo G, Cosenza A, Vicenzo L, Monaco L, Torelli F, Basciotti A, Brillantino A, Marra A: Total gastrectomy for gastric cancer: can the type of lymphadenectomy condition the long-term results? Supp/ Tumori 2005, 4:\$84-S85. Article in Italian.

17. Du XH, Li R, Chen L, Shen D, Li SY, Guo Q: Laparoscopy-assisted D2 radical distal gastrectomy for advanced gastric cancer: initial experience. Chin Med J (Engl) 2009, 122:1404-1407.

18. Tokunaga M, Hiki N, Fukunaga T, Nohara K, Katayama H, Akashi Y, Ohyama S, Yamaguchi T: Laparoscopy-assisted distal gastrectomy with D2 lymph node dissection following standardization-a preliminary study. J Gastrointest Surg 2009, 13:1058-1063.

19. Japanese Gastric Cancer Association: Japanese gastric cancer treatment guidelines 2010 (ver. 3). Gastric Cancer 2011, 14:113-123.

20. Kunisaki C, Makino H, Yamamoto N, Sato T, Oshima T, Nagano Y, Fujii S, Akiyama H, Otsuka Y, Ono HA, Kosaka T, Takagawa R, Shimada H: Learning curve for laparoscopy-assisted distal gastrectomy with regional lymph node dissection for early gastric cancer. Surg Laparosc Endosc Percutan Tech 2008, 18:236-241.

21. Yoo CH, Kim HO, Hwang SI, Son BH, Shin JH, Kim H: Short-term outcomes of laparoscopic-assisted distal gastrectomy for gastric cancer during a surgeon's learning curve period. Surg Endosc 2009, 23:2250-2257.

22. Zhang $X$, Tanigawa N: Learning curve of laparoscopic surgery for gastric cancer, a laparoscopic distal gastrectomy-based analysis. Surg EndosC 2009, 23:1259-1264

23. Sato H, Shimada M, Kurita N, Iwata T, Nishioka M, Morimoto S, Yoshikawa K, Miyatani T, Goto M, Kashihara H, Takasu C: Comparison of long-term prognosis of laparoscopy-assisted gastrectomy and conventional open gastrectomy with special reference to D2 lymph node dissection. Surg Endosc 2012, 26:2240-2246.

24. Yasuda K, Shiraishi N, Etoh T, Shiromizu A, Inomata M, Kitano S: Long-term quality of life after laparoscopy-assisted distal gastrectomy for gastric cancer. Surg Endosc 2007, 21:2150-2153.

25. Liang Y, Li G, Chen P, Yu J, Zhang C: Laparoscopic versus open gastrectomy for early distal gastric cancer: a meta-analysis. ANZ J Surg 2011, 81:673-680.

26. Hur H, Jeon HM, Kim W: Laparoscopy-assisted distal gastrectomy with D2 lymphadenectomy for T2b advanced gastric cancers: three years' experience. J Surg Oncol 2008, 98:515-519.

27. Shuang J, Qi S, Zheng J, Zhao Q, Li J, Kang Z, Hua J, Du J: A case-control study of laparoscopy-assisted and open distal gastrectomy for advanced gastric cancer. J Gastrointest Surg 2011, 15:57-62.

doi:10.1186/1477-7819-10-248

Cite this article as: Chen et al:: Laparoscopy-assisted versus open D2 radical gastrectomy for advanced gastric cancer without serosal invasion: a case control study. World Journal of Surgical Oncology 2012 $10: 248$

\section{Submit your next manuscript to BioMed Central and take full advantage of:}

- Convenient online submission

- Thorough peer review

- No space constraints or color figure charges

- Immediate publication on acceptance

- Inclusion in PubMed, CAS, Scopus and Google Scholar

- Research which is freely available for redistribution 